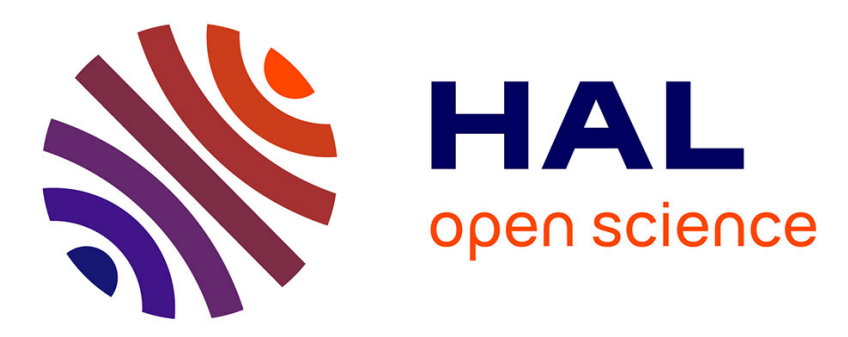

\title{
Getting Ready for the Fourth Industrial Revolution: Innovation in Small and Medium Sized Companies
}

\author{
Lise Lillebrygfjeld Halse, Eli Fyhn Ullern
}

\section{To cite this version:}

Lise Lillebrygfjeld Halse, Eli Fyhn Ullern. Getting Ready for the Fourth Industrial Revolution: Innovation in Small and Medium Sized Companies. IFIP International Conference on Advances in Production Management Systems (APMS), Sep 2017, Hamburg, Germany. pp.247-254, 10.1007/9783-319-66923-6_29. hal-01666192

\section{HAL Id: hal-01666192 \\ https://hal.inria.fr/hal-01666192}

Submitted on 18 Dec 2017

HAL is a multi-disciplinary open access archive for the deposit and dissemination of scientific research documents, whether they are published or not. The documents may come from teaching and research institutions in France or abroad, or from public or private research centers.
L'archive ouverte pluridisciplinaire HAL, est destinée au dépôt et à la diffusion de documents scientifiques de niveau recherche, publiés ou non, émanant des établissements d'enseignement et de recherche français ou étrangers, des laboratoires publics ou privés. 


\title{
Getting ready for the fourth industrial revolution: Innovation in Small and Medium Sized Companies
}

\author{
Lise Lillebrygfjeld Halse $^{1}$ and Eli Fyhn Ullern ${ }^{2}$ \\ ${ }^{1}$ Molde University College, Specialized University in Logistics, Molde, Norway \\ lise.1.halse@himolde.no \\ ${ }^{2}$ SINTEF, Trondheim, Norway \\ eli.fyhn.ullern@sintef.no
}

\begin{abstract}
Companies are currently preparing for the fourth industrial revolution, which is envisioned to radically change manufacturing processes, logistics and business models in global manufacturing networks. Previous research have emphasized the need to respond to the changing landscape of the digital economy in dynamic and innovative ways. This study aims at exploring how small and medium-sized companies are prepared to meet this opportunity and challenge. In order to do this we have applied insights from innovation theories and empirical findings from eight companies that are part of two industrial clusters. The findings in this study indicate that even though most of the case companies have ambitions to position themselves in a new digital landscape, they prepare themselves differently. We see that organizations that has progressed furthest in implementing Industry4.0 related concepts are the ones that make actively use of their external network in cooperation and sharing knowledge. These companies also have managed the balance between exploration and exploitation internally, where employees are both engaged in efficient manufacturing of existing products and product development. Consequently, we claim that both openness and organizational ambidexterity is vital for successful implementation of Industry 4.0.
\end{abstract}

Keywords: Innovation, Networks, Organizational ambidexterity, Implementation, Industry 4.0, Digitization

\section{Introduction}

The term "Industrie 4.0" originates from a governmental high-tech strategy in Germany, promoting the computerization of manufacturing [1]. This strategy which is referred to as the fourth industrial revolution, includes initiatives termed the Industrial Internet, Factories of The Future, and Cyber Physical Systems (CPS). The accelerated use of Internet of Things (IoT)-technologies is a driving force for this development [2]. Industry 4.0 encompasses a broad range of technologies and concepts, and is generally referred to as digitization. In the context of manufacturing, Industry 4.0 focuses on intelligent products and production processes [3]. In the envisioned factory of the future, or smart factory, CPS will enable communication between machines, products and humans. The products are intelligent and customized, to accommodate for the increased

adfa, p. 1, 2011.

(C) Springer-Verlag Berlin Heidelberg 2011 
need for rapid product development, flexible production and increasingly complex environments [4]. According to Brettel et al, this development leads to an increased importance of collaborative manufacturing and collaborative development environments, especially for Small and Medium Enterprises (SME) [3].

A challenge for manufacturers is their ability to keeping up with escalating technological change [5]. This applies not only the purely technical aspects, but involves the socio-technological systems, as intelligently networked objects in manufacturing is expected to constitute tasks distributed in time, space and content, and thereby change the content of work [6]. This will require new competence as well as increased worker flexibility, and the design of systems in the age of Industry 4.0 needs to be human centered in all parts of the manufacturing network [1], as the fourth industrial revolution aims at creating synergetic collaboration between humans and machines [7]. Hence, implementing Industry 4.0-concepts, requires not only implementing new technology and infrastructure, but also to adopt a completely different organizational setup, and a set of processes that are different from those found in traditional manufacturing [8]. This will lead to the development of innovative communication, different competence requirements, and interdisciplinary collaboration [7]. Moreover, the introduction of digital technology is expected to create unseen and unexpected fault lines, and also accelerate the pace of innovation [9].

With this as a point of departure, we may consider the implementation of concepts from the fourth industrial revolution as an open process that requires innovation capabilities inside the organization, as well as an openness for collaboration with other companies in a network, e.g. other cluster companies. Hence, in the following we will present theories addressing innovation internally to organizations, and innovation in the digital age with intensified networking.

\section{$2 \quad$ Literature review}

\subsection{Innovation in organization}

March claimed that for long-time survival, firms need to configure organizational resources to exploit existing assets and positions in a profit-producing way, while simultaneously explore new technologies and markets [10]. In this lies a fundamental tension between what he terms exploitation and exploration. Furthermore, firms are confronted with the basic problem of having sufficient exploitation to secure its current viability while engaging in enough exploration to ensure future viability. Several streams of literature have sought to address this fundamental problem. One of them is the literature on dynamic capabilities that is concerned about companies" "ability to sense, seize and reconfigure organizational assets to adapt to changed environmental conditions" [11].

According to O'Reilly and Tushman [12], the ability to balance exploitation and exploration, that is being ambidextrous, is at the core of dynamic capabilities. Managers must sense changes in the organization's environment, including potential changes in technology, market and regulation, and be able to act on the opportunities and threats by reconfiguring the organization's assets [13]. 
How do firms manage to balance this tension between exploration and exploitation? O' Reilly and Tushman [11] claim that ambidexterity requires commitment of resources to exploratory projects and establishing separate but aligned organizational units for exploitation and exploration, and these should have aligned organizational architectures. Here, leadership is essential in resolving the tensions arising from the two separate units and architectures. O'Reilly and Tushman stress that the organization's strategy needs to reflect an importance of both exploration and exploitation that is articulated through shared vision and provide a common identity. Furthermore, they suggest building senior teams that are committed to the ambidextrous strategy, which had incentives to both explore and exploit. Based on the above, we see that the strategic choices by the leaders of an organization are essential for facilitating innovation for future competitiveness, while exploiting existing assets to secure running profit. This comprise the dynamic capabilities of a company [14], which is necessary to survive in the long run [15]. However, a criticism to the literature on dynamic capabilities and organizational ambidexterity, is that it views the organization in isolation, and does not take into account that innovativeness and organizational survival is dependent on the organization being a part of a larger network of companies [16]. This view of innovation is challenged by the network view of innovation, as the concept of open innovation, which will be addressed in the following.

\subsection{Innovation in the age of digitization}

Digitalization can be referred to as generation of new knowledge that could not be possible without digital technologies [17] Yoo et al [18] defines digital innovation as "the carrying out of new combinations of digital and physical components to produce novel products" (p. 725), which reflect a product centered view of digitization. Furthermore, they claim that adoption of pervasive digital technology is fundamentally reshaping organizations, and change the very nature of innovation in organizations. Yoo et al [9] claim that this happens in three ways: The importance of digital technology platforms, the emergence of distributed innovations, and the prevalence of combinatorial innovations ( $p$ 1400). In this study, we focus on the second; distributed innovations.

Distributed innovations mean that innovation activities are spread across multiple organizations, as opposed to the view that innovation processes takes place internally in organizations. This is in line with the concept of open innovation, which Chesbrough define as "the use of purposive inflows and outflows of knowledge to accelerate internal innovation and expand the markets for external use of innovation" [19]. When introduced, this represented a paradigm shift from the closed view where innovative process was confined within the company's borders, where internal innovation activities led to internally developed products and services that subsequently were distributed by the firm. In contrast, in the open innovation model, companies use external as well as internal ideas and knowledge to advance their technology and combine ideas into architectures and systems in order to create value [19]. According to Yoo et al [9], digital technology intensifies the aspect of innovation emphasized by the open innovation model, in that heterogeneity as well as the need for dynamically balancing and integrating of knowledge resources, becomes even more important. However, their arguments 
are strongly based on technology and use of digital tools. Moreover, the recent examples of innovation associated with concepts from digitization and Industry 4.0 is largely based on companies that are parts of a networks with a large number of companies and are delivering products and services to a mass market. There is a lack of knowledge shedding light on how small and medium sized companies being part of a regional innovation networks, are approaching the fourth industrial revolution. Moreover, there are few studies exploring what role the innovation processes plays in the implementing of concepts and technology related to Industry 4.0. This study aims at filling this gap.

\section{$3 \quad$ Methodology}

In this study, we aim at contributing to filling the gaps in the literature by adopting a multiple case study design [20,21]. We have carried out case studies in order to gain insight into how small and medium-sized companies in regional clusters are prepared to meet opportunities and challenges represented by the fourth industrial revolution, from an innovation perspective. Data was collected through semi-structured interviews with top managers in eight manufacturing companies, representing two regional clusters based in North-West Norway. Additional data was collected in workshops and meetings with cluster companies.

The data collection aimed at revealing how the companies looked upon Industry 4.0 and related concepts, their strategy for meeting this challenge and opportunity, and their thoughts about how far they had come in implementing Industry 4.0-related concepts internally in their organization. Moreover, we wanted to map their innovation process internally, as well as how they involved other companies external to their organization. Finally, the respondents were asked to reflect upon the possible challenges for moving into the next digital age.

\section{$4 \quad$ Case companies}

The case companies were selected from two industrial clusters in the North West part of Norway, representing a high-cost manufacturing context. Both clusters are part of the Norwegian cluster program, where both are at first out of three levels, being clusters at an early stage of development. The establishment of both clusters have created important arenas for networking and competence building. The cluster projects were established in a situation with little cooperation between companies, and have quickly shifted into a new way of working characterized by openness, trust and cooperation.

Cluster A is a cluster covering 38 companies within several industries, as manufacturers of equipment and services to the offshore and maritime industry, plastic component manufacturers, process industry, electronics companies, consultants, logistics companies, among others. Cluster B is an industry cluster including 12 companies manufacturing finished goods, mainly furniture. The companies delivers the products mostly to wholesalers, and the end-market covers private customers and contract customers nationally as well as globally. 
Both clusters focus on Industry 4.0 as a part of their cluster strategies, although in slightly different ways. Cluster A has named the concept "Industrial Internet" as the main strategy of the cluster, and have facilitated several initiatives involving cluster companies that aims at building competence in this field. This involves IoT (Internet of Things), Big Data, sensory, 3D printing, VR (Virtual Reality), AR (augment reality), AI (Artificial Intelligence), robotics and automation. Lately, they have focused mainly on how digital insights on these new technologies may represent new sustainability business models, products and services.

Cluster B builds on a common desire to build stronger international competitiveness based on strong brands among their members. They have oriented themselves towards digital business models, and are currently organizing an educational program for their members, focusing on this issue. Both clusters are involved as industry partners in competence building projects addressing issues associated with Industry 4.0, and aim at establishing new projects with research groups nationally as well as internationally.

\section{$5 \quad$ Findings}

\subsection{The concept of Industry 4.0}

The concept "Industry 4.0" itself was well known among all the case companies, which should be expected based on the increased attention surrounding this topic the last years, especially from the two cluster organizations. The companies views Industry 4.0 and related topics as being described as both an opportunity but also a necessity in order to stay competitive. Six of the companies describes Industry 4.0 as a part of their strategies and ambitions for the future. However, at this point the implementation of new technology in manufacturing and digital integration with external actors, is relatively limited in the majority of the companies.

Although our case companies describes Industry 4.0 as an opportunity, it is also considered as a fuzzy concept for SMEs. Several of the companies were uncertain what the implications of the recent development in digitalization would be, which is reflected in one of the CEOs reflection: "Industry 4.0 technologies is first and foremost relevant as a mean [towards a goal]", and another one pointed out that "we are not there [industry 4.0] yet". These respondents were not clear about how to position themselves in relatiion to Industry 4.0, which reveals a gap between the expressed ambition and their current situation.

Furthermore, the findings revealed that companies perceived Industry 4.0 and the associated technology differently, and put different emphasize on their internal manufacturing processes or the product itself. Here, we could observe differences between the two clusters. Firms from cluster B gave more attention to key enabling technologies associated with their products, as the integration of sensors giving the opportunity to collect user data. Companies from cluster A focused more on the use of new technologies that could improve the efficiency of their manufacturing processes. 


\subsection{Innovation}

\section{Exploration and exploitation.}

Based on the theory presented above, we assessed the case companies' innovation strategy. It varied significantly how companies carried out their product development processes related to existing and new products, while carrying out their daily business. On the most explorative side, the founder and manager of one of the companies expressed their strategy in these words:

"Our success and focus has been not to only sell the original [basic] product, but to sell the complete product. Our main motive has been to develop new technology that is adapted to the market."

The company is continuously working with development of new business models and the implementation of new technologies. This strategy turned out to be important when they experienced that their main product lost market shares the recent years. Then they could turn to their new and innovative products, which they had worked with "on the side". In this company, employees were heavily involved in the innovation processes: "It has been important to develop a culture in the company were people want to develop themselves". In addition to this company, three other companies in the study could be characterized as being explorative in the sense that they seek new opportunities, and are able to develop new products while attending to their existing business.

In contrast, the CEO of another regional company reported that their innovation processes mainly took place outside of the company, from where they purchased new designs and concepts. This company also reported low level of technology use: "there is not much technology around here", and was mainly concerned about upgrading the existing ERP system. Another case company in the same cluster and producing relatively similar products to the same market, had a different ambition and strategy regarding technology use, and was currently investing in new data driven manufacturing equipment. This illustrate that there are other factors than the characteristics of the product, market or manufacturing context that are governing how a company prepare for implementing new technology.

\section{Networks}

Being members of two clusters organizations, the companies has opportunities to participate in arenas where knowledge is being shared. However, we found that the use of these arenas varied considerably among the case companies, and the general impression was that the companies that were oriented towards internal innovation, also were the ones most actively drawing on external networks. Not only within the clusters, but also between the two clusters and through other networks. One respondent from cluster A illustrated this by the statement: "If you are going to be innovative, you have to work with other companies". This company had recently developed an innovative product that was a result of cooperation with internal personnel, a company from another industry (cluster A), and an external actor. Another respondent claimed that "a network have two sides: both the social responsibility and contacts in the network are important." 
Furthermore, both clusters aim at increasing the member's knowledge within the field of digitization, new business models, and innovation. The clusters have established educational programs in cooperation with universities and university colleges within this field. Several respondents reported that they were part of these programs, and for one of the companies, this was the only arena for cluster participation.

\section{Discussion and conclusions}

This study has examined how eight manufacturing SMEs in two clusters in North-West Norway prepare themselves for the future of Industry 4.0. Contrary to the recent literature addressing Industry 4.0, we have based our study on innovation literature. In this literature, the terms exploration and exploitation are terms that are mostly used as terms inside the companies, and innovation in network has been regarded as an alternative approach. In our study we have seen that this goes hand in hand; the companies that handle the ambidexterity of innovation, that means being able to explore new business opportunities as well as attending to and improving their current activities, also are the ones that draw heavily on external networks in their innovation processes. This is illustrated by a quote from one of the managers; "you have to attend to the daily activities, but you have to be able to look forward at the same time". O'Reilly and Tushman [11] claim that companies need to carry out the explorative activities in a separate organizational unit, which is done in two of our case companies. However, our findings from these small and medium-sized companies indicate that several of them were able to combine both exploration and exploitation, without having a separate organizational unit for exoloration activities, and in fact were the ones that were most innovative and had come furthest in implementing new technology in their products.

Moreover, we see that companies that have managed the balance between exploration and exploitation internally also are the ones that make actively use of their external network in cooperation and sharing knowledge, and that has progressed furthest in implementing Industry 4.0 related concepts. This demonstrate and confirms the claims made by Yoo et al [9], that the implementation of digital technology intensifies the need of open innovation model. Hence, both openness and organizational ambidexterity seems to be important for implementation of Industry 4.0 for small and medium sized companies, which are challenged by limited resources for explorative activities.

The implications of our findings is that the first step of implementing/orienting towards Industry 4.0 is to create a culture for innovation in the organization with employee involvement, while establishing collaboration with other companies in networks. Moreover, the company needs an explicit strategy and ambitions towards implementing enabling technology. Eventually, our findings emphasize the importance of being part of clusters and extra cluster networks when preparing for the fourth industrial revolution.

Acknowledgments. We thank the Manufacturing Network 4.0 project, financed by the Norwegian research Council, for support of the research presented in this paper. 


\section{References}

1. Zuehlke, D., SmartFactory-Towards a factory-of-things. Annual Reviews in Control, 2010. 34(1): p. 129-138.

2. Porter, M.E. and J.E. Heppelmann, How smart, connected products are transforming companies. Harvard Business Review, 2015. 93(10): p. 96.

3. Brettel, M., et al., How Virtualization, Decentralization and Network Building Change the Manufacturing Landscape: An Industry 4.0 Perspective International Journal of Mechanical, Aerospace, Industrial, Mechatronic and Manufacturing Engineering, 2014. 8(1): p. 37-44.

4. Vyatkin, V., et al., Now that's smart! Industrial Electronics Magazine, IEEE, 2007. 1(4): p. 17-29.

5. Murray, A. 5 things you didn't know about the Fortune 500, Fortune 500 Facts. 2015 [cited 2016 April]; Available from: http://fortune.com/2015/06/04/fortune-500-facts/

6. Bauer, W., et al., Transforming to a Hyper-connected Society and Economy Towards an "Industry 4.0". Procedia Manufacturing, 2015. 3: p. 417-424.

7. Dombrowski, U. and T. Wagner, Mental Strain as Field of Action in the 4th Industrial Revolution. Procedia CIRP, 2014. 17: p. 100-105.

8. Slama, D., et al., Enterprise IoT. 2016, Sebastopol, CA: O'Reilly Media Inc.

9. Yoo, Y., et al., Organizing for Innovation in the Digitized World. Organization Science, 2012. 23(5): p. 1398-1408.

10. March, J.G., Exploration and Exploitation in Organizational Learning. Organization Science, 1991. 2(1): p. 71-87.

11. O'Reilly, C.A. and M.L. Tushman, Organizational ambidexterity in action: How managers explore and exploit. . California Management Review, 2011. 53(4): p. 522.

12. O'Reilly Iii, C.A. and M.L. Tushman, Ambidexterity as a dynamic capability: Resolving the innovator's dilemma. Research in Organizational Behavior, 2008. 28: p. 185-206.

13. Teece, D.J., Explicating dynamic capabilities: the nature and microfoundations of (sustainable) enterprise performance. . Strategic Management Journal, 2007. 28(13): p. 1319-1350.

14. Teece, D., J., G. Pisano, and A. Shuen, Dynamic capabilties and stretegic management. Strategic Management Journal (1986-1998), 1997. 18(7): p. 509-509.

15. Uotila, J., et al., Exploration, exploitation, and financial performance: analysis of S\&P 500 corporations. Strategic Management Journal, 2009. 30(2): p. 221-231.

16. Håkansson, H. and I. Snehota, No business is an island: The network concept of business strategy. Scandinavian Journal of Management, 1989. 5(3): p. 187-200.

17. Dougherty, D. and D.D. Dunne, Digital Science and Knowledge Boundaries in Complex Innovation. Organization Science, 2012. 23(5): p. 1467-1484.

18. Yoo, Y., O. Henfridsson, and K. Lyytinen, The New Organizing Logic of Digital Innovation: An Agenda for Information Systems Research. Information Systems Research, 2012. 21(4): p. 724-773.

19. Chesbrough, H., Open innovation: A new paradigm for understanding industrial innovation in Open Innovation, Research ing a New Paradigm, H. Chesbrough, W. Vanhaverbeke, and J. West, Editors. 2006, Oxford University Press: New York, NY p. 1-12.

20. Yin, R.K., Case study research: design and methods. 2009, Los Angeles: Sage. XIV. 21. Stake, R.E., Multiple case study analysis. 2006, New York: Guilford Press. 